\title{
Inventarisasi Awal Jenis Amfibi di Kawasan Malibo Anai (Provinsi Sumatera Barat) dengan Keterangan Habitatnya
}

\author{
Fitra Arya Dwi Nugraha ${ }^{(*)}$, Yunico Amardi2 ${ }^{2)}$, Malvino Kentino ${ }^{3)}$, Katon Agusdi $^{4)}$, Roni Rinaldo ${ }^{5)}$ \\ 123 Jurusan Biologi, Fakultas Matematika dan Ilmu Pengetahuan Alam, Universitas Negeri Padang \\ *email: fitraaryadn@fmipa.unp.ac.id* \\ email: nico4four@gmail.com \\ email: mallvinokentino17032023@gmail.com \\ email: katonagusdi2@gmail.com \\ ${ }^{5}$ Balai Konservasi Sumber Daya Alam Sumatera Barat \\ email: ronirinaldo771@gmail.com
}
APA Citation: Nugraha, F. A. D., Amardi, Y., Kentino, M., Agusdi K., Rinaldo, R. (2021). Inventarisasi Awal Jenis Amfibi di Kawasan Malibo Anai (Provinsi Sumatera Barat) dengan Keterangan Habitatnya. Quagga: Jurnal Pendidikan dan Biologi, 13(1), 82-87. doi: 10.25134/quagga.v13i1.3738.

Received: 06-12-2020

Accepted: 28-12-2020

Published: 01-01-2021

\begin{abstract}
Abstrak: Tujuan dari penelitian ini adalah untuk menemukan amfibi yang hidup di kawasan objek wisata alam Malibo Anai. Wilayah tersebut terletak di kaki gunung Tandikek di provinsi Sumatera Barat. Karena resor ini berfungsi sebagai objek wisata alam, resor ini mempertahankan hutan primer yang ada di sebagian besar kawasan yang mungkin menyediakan rumah yang layak bagi amfibi dan kelompok hewan lainnya. Survei dilakukan pada Januari dan Juli 2020. Kami mencatat 22 spesies amfibi di tiga habitat. Sebagian besar amfibi ditemukan di dekat genangan air. Satu spesies dari family Rhacophoridae, Zhangixalus achantharrhena dan satu dari family Ranidae, Pulchrana fantastica ditemukan dan dilaporkan secara formal untuk pertama kalinya di luar lokasi tipe mereka. Bersamaan dengan penelitian ini, kami juga mencatat 2 jenis ular dan beberapa jenis cicak jari lengkung yang cryptic. Area studi tersebut akan menjadi tempat yang baik untuk melakukan penelitian biologi dan ekologi
\end{abstract}

Kata kunci: Herpetofauna; keanekaragaman; Sumatera; ekologi; taksonomi.

Abstract: The objective of this study is to invent amphibians inhabiting the region of natural tourism object of Malibo Anai. The region is located in the foot of mountain Tandikek in Sumatera Barat province. Since this resort serve as natural tourism object, the resort maintains primary forest existed in most of the area which might provide an appropriate home for amphibians and other group of animals. The survei was conducted in January and July 2020. We recorded 22 species of amphibians in three types of habitat. Most of amphibians were found near the standing body water. A species of Rhacophoridae, Zhangixalus achantharrhena and of Ranidae, Pulchrana fantastica were found and reported formally for the first time outside of their type localities. Along with this study, we also recorded snakes and several cryptic bent-toed geckoes. The area of study would serve as a good place to conduct research on biology and ecology.

Keywords: Herpetofauna; diversity; Sumatera; ecology; taxonomy.

\section{PENDAHULUAN}

Sumatera merupakan salah satu hotspot biodiversitas di kawasan Sunda. Penulusuran kami pada beberapa database penyedia data amfibi (Amphibiaweb 2020; Frost 2020) dan pada beberapa artikel menunjukkan bahwa Sumatera memiliki jenis Anura sebanyak 117 spesies. Namun pada tahun 2001, dibandingkan dengan Borneo dan Peninsular Malaysia, Sumatera masih tertinggal jauh (vs Borneo 148 spesies dan Peninsular Malaysia 101). Ini menunjukkan bahwa biodiversitas Sumatera masih belum tereksplorasi dengan baik (Inger dan Voris, 2001).

Eksplorasi di Sumatera telah banyak dilakukan dalam beberapa tahun terakhir. Pekerjaan tersebut menghasilkan beberapa deskripsi spesies baru, genus baru, deskripsi ulang spesies dan penemuan spesies yang hilang selama bertahun-tahun. Sebagai contoh deskripsi spesies baru (Wostl et al, 2017; Teynie et al, 2010; Harvey et al, 2017a, $\underline{\text { b; Munir et al, }}$ 2018; Atmaja et al, 2019); genus baru dengan beberapa spesies baru (Arifin et al, 2018; $\underline{\text { Smart }}$ et al, 2017); deskripsi ulang spesies (Harvey et 
al, 2016); dan penemuan spesies yang telah lama tidak dijumpai hampir 129 tahun (Putra et al,, 2020). Banyak jenis yang dideskripsikan berdasarkan spesimen tipe yang berasal dari Sumatera Barat, seperti Cyrtodactylus agamensis, Hemiphyllodactylus margarethae, Lycodon subbanulatus, Bufo totol, Bufo sumatranus, Megophrys parallela, Chalcorana parvaccola.

Inventarisasi di Sumatera Barat juga sudah beberapa kali melalui beberapa penelitian yang komprehensif. Teynie et al, (2010) mengoleksi spesies dari beberapa wilayah di Sumatera Barat dan mendapatkan 61 spesies amfibi dengan deskripsi satu spesies baru. Inger dan Iskandar (2005) juga melakukan survei pada 3 lokasi, yang disebut dengan Sumatera Padang, Payakumbuh, Lubuk Selasih; mendapatkan 28 spesies serta mendeskripsikan satu jenis baru. Mengingat masih rendahnya diversitas yang dieksplorasi, maka kontribusi penelitian inventarisasi sangat penting dilakukan. Penelitian ini dilakukan untuk menambah koleksi spesies dari lokasi yang belum pernah disurvei sebelumnya.

\section{METODOLOGI PENELITIAN}

Penelitian di lakukan di kawasan wisata alam Malibo Anai (latitude $0^{\circ} 28^{\prime} 48.6258^{\prime \prime} \mathrm{N}$, $100^{\circ} 19^{\prime} 13.7244 " E$, ketinggian $612 \mathrm{mdpl}$ ) (Gambar 1) pada bulan Januari dan Juni 2020. Kami menggunakan metode visual encounter survei (Campbell dan Christman 1982) untuk secara efektif mengeksplorasi area yang luas. Habitat yang tereksplorasi selama survei ini adalah lantai hutan yang berserasah, kolam musiman dimana kondisi air saat survei tidak terlalu banyak (sekitar $4 \mathrm{~cm}$ dari dasar kolam yang berserasah dan berlumpur), dan sungai berbatuan besar dengan lebar sungai kira-kira 8 meter. Survei dilakukan malam hari mulai pukul 08.00 hingga 00.00. Spesies yang telah ditangkap akan dimasukkan ke dalam plastik akan dilepaskan keesokan harinya setelah proses identifikasi selesai. Identifikasi jenis dilakukan dengan menggunakan buku panduan identifikasi terkait (Iskandar, 1998; Inger dan Stuebing, 2005) serta artikel-artikel terkait yang berisi deskripsi spesies (Arifin et al, 2018a, $\underline{\text { b; }}$ Teynie et al, 2010; Inger dan Iskandar, 2005). Data disajikan dalam bentuk tabel dan gambar dan dianalisis secara deskriptif dengan menjelaskan spesies yang ditemui dan habitat penemuannya.

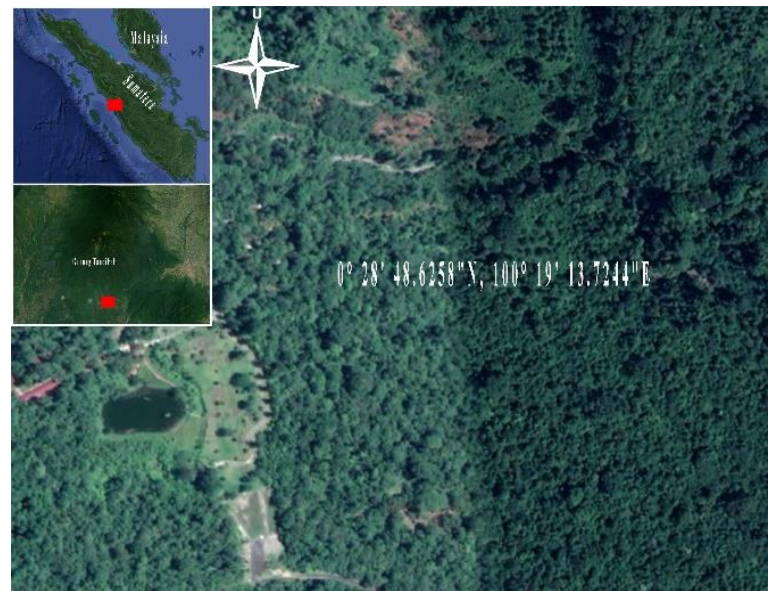

Gambar 1. Lokasi penelitian (ditunjukkan dengan tandan merah pada peta insert), merupakan kaki gunung dari gunung Tandikek, provinsi Sumatera Barat. Insert atas: pulau Sumatera; insert bawah: menunjukkan kaki gunung Tandikek sebagai lokasi penelitian.

\section{HASIL DAN PEMBAHASAN}

Kami mendapat 22 spesies amfibi yang masuk ke dalam 6 family (Tabel. 1 dan Gambar 2), 2 spesies ular (Trimeresurus albolabris dan Xenochropis trianguligerus) dan beberapa spesies cryptic dari Cyrtodactylus (Gambar 3). Jenis amfibi yang paling banyak dijumpai adalah Leptophryne borbonica yang mendiami sungai bebatuan. Teynie et al, (2010) melalui surveinya di Sumatera mendapatkan 61 jenis amfibi dan 147 jenis reptil di Sumatera Barat. Sementara itu, Inger dan Iskandar (2005) mendapatkan 28 spesies Anura. Meskipun tidak semua spesies dari 2 penelitian di atas didapatkan kembali pada penelitian ini, namun hasil penelitian ini menambahkan 2 spesies yang tidak ditemukan atau dideskripsikan pada penelitian tersebut, yaitu Pulchrana signata, dan Pelophryne signata. Satu spesies dari katak pohon (P. pseudotilophus) yang terdata pada penelitian kami tidak terdata pada penelitian sebelumnya karena deskripsi spesies tersebut adalah pada tahun 2014.

Bufonidae. Ada 3 spesies yang dijumpai dalam family Bufonidae, dimana yang paling banyak dijumpai adalah $L$. borbonica. Spesies tersebut paling banyak dijumpai ditengah sungai dengan di atas batu-batu besar. Diameter batu substrat berkisar dari $60-125 \mathrm{~cm}$. Jantan dari spesies ini banyak melakukan panggilan kawin di posisi yang deras aliran airnya. Selain disungai berbatuan, jenis ini juga dapat ditemui di serasah di tengah hutan $(n=1)$; di permukaan tanah di 
jalan perlintasan dimana vegetasi di sampingsampingnya adalah herba didominasi oleh pakupakuan (1); di atas tanah di tengah-tengah semak di samping sungai kecil tidak berbatuan dengan aliran lambat (1). Spesies $P$. aspera di temukan di pinggi sungai bebatuan besar. Spesies $P$. signata ditemukan di atas daun paku-pakuan yang menempel pada batang pohon dengan ketinggian dari atas permukaan tanah sekitar 1 $\mathrm{m}(\mathrm{n}=1)$; satu individu lainnya juga ditemukan di atas daun paku-pakuan sekitar $60 \mathrm{~cm}$ di atas permukaan tanah, ditebing samping jalan perlintasan hutan. Di antara spesies dalam family Bufonidae, $L$. borbonica sangat menarik dalam hal habitatnya. Beberapa peneliti menunjukkan ketinggian persebaran habitatnya luas mulai dari: di bawah $400 \mathrm{mdpl}$ (Inger dan Stuebing, 2005), 700-870 mdpl (Ardiansyah et al, 2014; Erfanda et al, 2019), $1400 \mathrm{mdpl}$ (Hamidy et al, 2018), dan 2019 mdpl (Nugraha et al, 2019). Persebaran yang luas ini merupakan sesuatu yang menarik untuk diteliti lebih jauh lagi.

Dicroglossidae. Ada 4 spesies Limnonectes yang dijumpai dalam family Dicroglossidae. $L$. kuhlii dapat dijumpai di sungai berbatuan ataupun kolam musiman. L. blythii hanya ditemukan di sungai berbatuan berada di dekat pinggir sungai, di bagian air yang tidak mengalir. L. macrodon dan L. malesianus juga ditemukan ditengah kolam musiman dengan substrat dasar berupa serasah dan lumpur.

Megophrydae. Dua spesies yang ditemukan dalam family ini adalah $M$. nasuta dan $L$. hasseltii. Empat individu M. nasuta semuanya dijumpai di lantai hutan yang berserasah. Spesies ini sangat mirip dengan daun yang kering di lantai hutan tersebut.. Satu individu $L$. hasseltii

Tabel 1. Daftar jenis yang ditemukan di Malibo Anai.

\begin{tabular}{|c|c|c|}
\hline No & Family & Spesies \\
\hline 1 & Bufonidae & Leptophryne borbonica (Tschudi, 1838) \\
\hline 2 & & Phrynoidis aspera (Gravenhorst, 1829) \\
\hline 3 & & Pelophryne signata (Boulenger, 1985) \\
\hline 4 & Ranidae & Pulchrana signata (Gunther, 1872) \\
\hline 5 & & Pulchrana fantastica Arifin, Cahyadi, Smart, Jankowski, and Haas, 2018 \\
\hline 6 & & Odorrana hosii (Boulenger, 1891) \\
\hline 7 & & Chalcorana chalconota (Schlegel, 1837) \\
\hline 8 & & C. rufipes (Inger, Stuart, and Iskandar, 2009) \\
\hline 9 & & Sylvirana cf. malayana Sheridan and Stuart, 2018 \\
\hline 10 & Rhacophoridae & Polypedates pseudotilophus Matsui, Hamidy, and Kuraishi, 2014 \\
\hline 11 & & P. macrotis (Boulenger, 1891) \\
\hline 12 & & P. leucomystax (Gravenhorst, 1829) \\
\hline 13 & & Rachoporus pardalis Gunther, 1858 \\
\hline 14 & & Zhangixalus achantharrhena (Harvey, Pemberton, and Smith, 2002) \\
\hline 15 & Megophrydae & Megophrys nasuta (Schlegel, 1858) \\
\hline 16 & & Leptobrachium hasseltii Tschudi, 1838 \\
\hline 17 & Dicroglossidae & Limnonectes kuhlii (Tschudi, 1838) \\
\hline 18 & & L. malesianus (Kiew, 1984) \\
\hline 19 & & L. macrodon (Dumeril and Bibron, 1841) \\
\hline 20 & & L. blythii (Boulenger, 1920) \\
\hline 21 & Microhylidae & Kalophrynus pleurostigma Tschudi, 1838 \\
\hline 22 & & Phrynella pulchra Boulenger 1887 \\
\hline
\end{tabular}

yang masih individu muda masih memiliki ekor yang sudah mulai tereduksi ditemukan ditengah sungai di atas batu dengan bagian tubuh muncul setengah badan ke permukaan. 
Microhylidae. Dua spesies dari family ini adalah Kalophrynus pleurostigma dan Phrynella pulchra. Spesies yang pertama ditemukan di lantai hutan berserasah $(n=1)$. Spesies yang kedua (4 individu) ditemukan di atas daun dengan diameter sekitar $10 \mathrm{~cm}$, dan $15 \mathrm{~cm}$ di atas permukaan tanah. Daun tersebut (tidak teridentifikasi spesiesnya) merupakan tumbuhan herba yang berada tepat di sekeliling pohon besar dan tinggi.

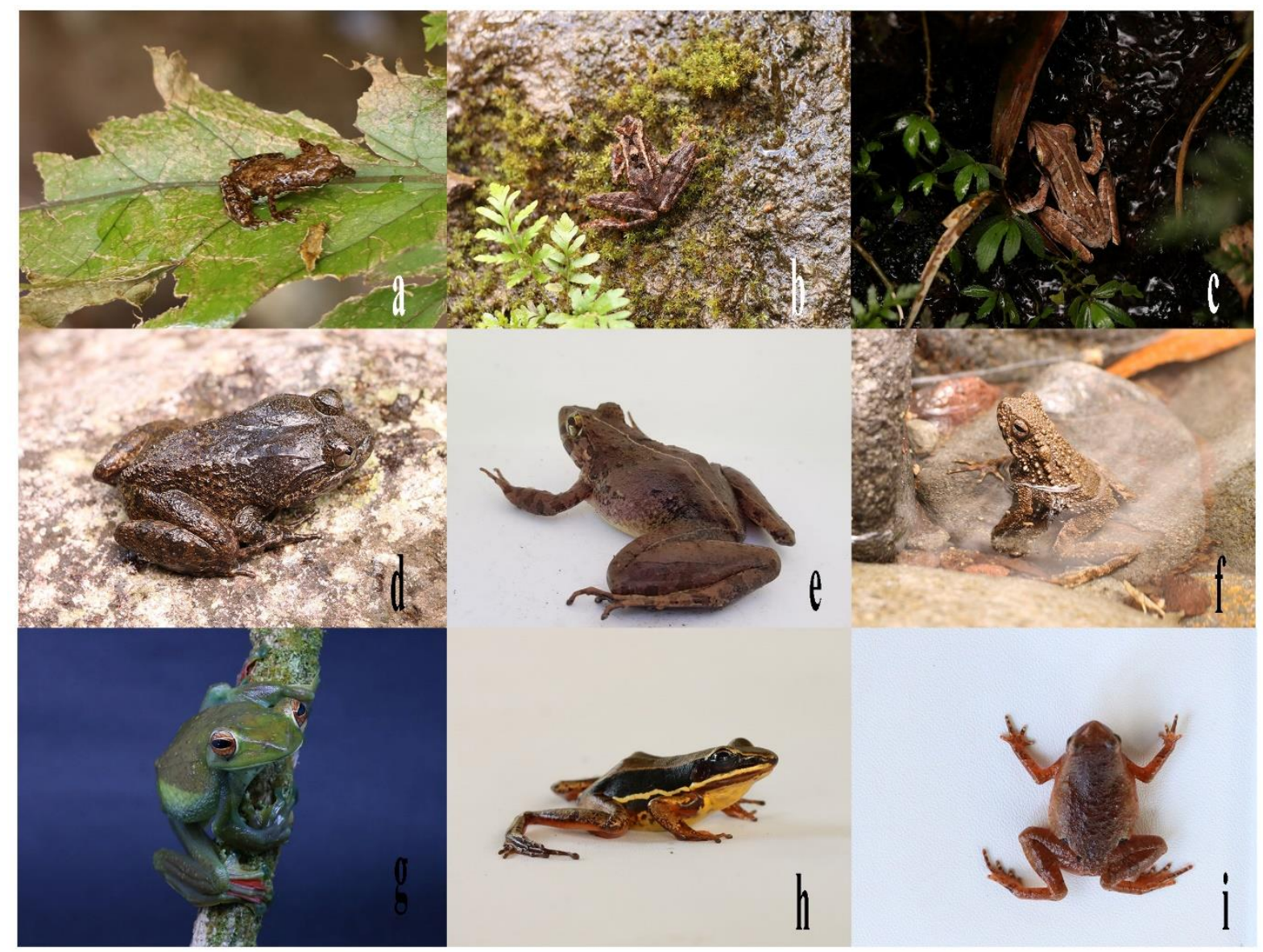

Gambar 2. Gambar 2. Sebagian jenis Anura yang ditemukan dalam penelitian. (a) Pelophryne signata, (b) L. borbonica, (c) P. macrotis, (d) L. kuhlii, (e) L. malesianus, (f) P. aspera, (g) Z. achantharrhena, (h) S. cf. malayana, dan (i) K. Pleurostigma.

Ranidae. Ada 6 spesies yang ditemukan dalam family ini. Grup Pulchrana dan Chalcorana ditemukan di sungai berbatuan, namun Chalcorana juga ditemukan di sepanjang aliran di samping jalan perlintasan. Pulchrana signata ditemukan di bebatuan bagian pinggir dari badan sungai dan $P$. fantastica ditemukan ditengah sungai di atas batu. Sedangkan Chalcorana rufipes dan $C$. chalconota ditemukan di atas daun di bagian pinggir dari kedua aliran air. Berbeda dari yang lainnya, $S$. cf. malayana ditemukan jauh dari badan air, yaitu di atas rumput dengan ketinggian sekitar $4 \mathrm{~cm}$, di area lapang tidak berpohon.

Rhacophoridae. Ada 5 spesies yang termasuk ke dalam Rhacophoridae. Semua spesies yang ditemukan berada di pinggir kolam musiman dengan posisi berada di atas daun atau sedang bertengger di batang pohon. Jenis $P$. leucomystax $(\mathrm{n}=2)$ ditemukan bertengger di batang pohon berkayu dengan diameter $8 \mathrm{~cm}$. Ketinggian dari atas permukaan tanah adalah sekitar $160-170 \mathrm{~cm}$. Jenis $P$. pseudotilophus $(\mathrm{n}=2)$ ditemukan di atas daun yang berada di atas kolam musiman tersebut, begitu juga dengan $R$. pardalis. Spesies yang paling tinggi posisinya adalah $Z$. achantherrhena dimana jenis ini $(n=1)$ didapatkan di atas daun dengan ketinggian hampir $2 \mathrm{~m}$ dari permukaan tanah dan sekitar 2,5 m dari permukaan air kolam musiman. Spesies Z. achnatharrhena sebelumnya hanya diketahui dari lokasi tipe spesimennya saja, yaitu Bengkulu pada ketinggian 1415 m (Harvey 
et al, 2002). Kami menambahkan persebaran distribusinya hingga Sumatera Barat dan ketinggian lebih rendah hingga $600 \mathrm{mdpl}$. Begitu juga dengan Pulchrana fantastica dimana sebelumnya hanya dilaporkan secara formal dari Aceh dan Sumatera Utara saja (Arifin et al, 2018). Kami menambahkan area distribusinya hingga Sumatera Barat. Kelompok amfibi memang menyukai daerah yang lembab dan berair seperti kolam (permanen/musiman), sungai, tanah yang lembab, lantai hutan yang berserasah, dan di pepohonan (ranting, batang, daun) (Kusrini, 2008).

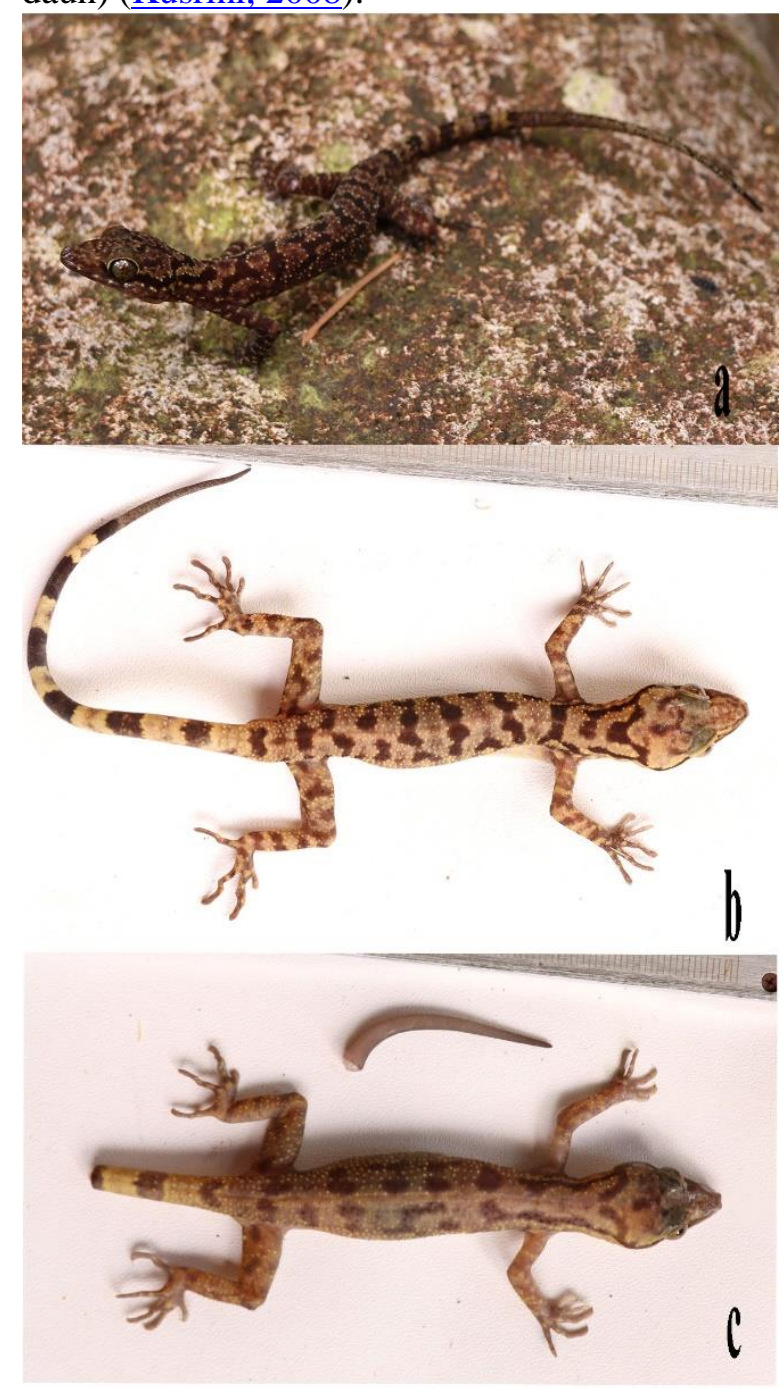

Gambar 3. Cicak jari lengkung genus Cyrtodactylus. (a) C. sp1; (b) C. sp2; (c) C. sp3.

\section{SIMPULAN}

Kami menemukan bahwa kawasan wisata alam Malibo Anai, provinsi Sumatera Barat memiliki jenis amfibi dan cicak jari lengkung yang beranekaragam. Lokasi ini sangat mendukung penelitian-penelitian jangka panjang seperti monitoring spesies atau observasi siklus hidup spesies.

\section{UCAPAN TERIMA KASIH}

Salah satu perjalanan survei dilakukan bersamaan dengan pelatihan survei dan preservasi di lokasi penelitian, sehingga ucapan terima kasih kami tujukan kepada pelatih dan peserta pelatihan tersebut: U Arifin, L Yodhi, L Rahmayani, M Iqbal, M Kamal, D Efendi, A Hamid. Terima kasih kepada Jurusan Biologi Universitas Negeri Padang yang telah memberikan dukungan finansial untuk pelaksanaan pelatihan survei amfibi di lokasi penelitian. Terima kasih kepada Lembaga Penelitian dan Pengabdian Kepada Masyarakat, Universitas Negeri Padang (LP2M UNP) yang telah memberikan dukungan finansial untuk pelaksanaan penelitian (Surat Keputusan: 184/UN35/LT/2020).

\section{REFERENSI}

AmphibiaWeb. 2020. https://amphibiaweb.org. University of California, Berkeley, CA, USA. Diakses 3 Desember 2020.

Ardiansyah, D., Auliandina, T., Putri, D. A., Noer, M. I. 2014. Kelimpahan Kodok jam Pasir Leptophryne borbonica Di Sepanjang Aliran Sungai Cisuren, Bodogol, Taman Nasional Gunung Gede Pangrango. BIOMA. 10 (2): 11-18.

Arifin, U., Cahyadi, G., Smart, U., Jankowski, A., Haas, A. 2018a. A new species of the genus Pulchrana Dubois, 1992 (Amphibia: Ranidae) from Sumatra, Indonesia. Raffles Bulletin of Zoology. 66: 277-299.

Arifin, U., Smart, U., Hertwig, S. T., Smith, E. N., Iskandar, D. T., Haas, A. 2018b. Molecular phylogenetic analysis of a taxonomically unstable Ranid from Sumatera, Indonesia, reveals a new genus with gastromyzophorous tadpoles and two new species. Zoosystematics and Evolution. 94 (1): 163-193.

Atmaja, V. Y., Hamidy, A., Arisuryanti, T., Matsui, M., Smith, E. N. 2018. A new species of Microhyla (Anura: Microhylidae) from Sumatra, Indonesia. Treubia. 45: 25-46.

Campbell, H. W \& Christman, S. P. 1982. Field techniques for herpetofaunal community analysis. Dalam Scott NJ Jr. (ed), Herpetological Communities. Wildlife Research Report, 13: 193-200. 
Erfanda, M. P., Septiadi, L., Devi, S. R., Hanifa, B. F. 2019. Distribution record of Leptophryne borbonica (Tschudi, 1838) (Anura: Bufonidae) from Malang, East Java: Description, Microhabitat, and Possible Threats. Journal of Tropical Biodiversity and Biotechnology. 4 (2): 8289.

Frost, D. R. 2020. Amphibian Species of the World: an Online Reference. Version 6.1. https://amphibiansoftheworld.amnh.org/in dx.php. Diakses 3 Desember 2020.

Hamidy, A., Munir, M., Mumpuni, M., Rahmania, M., Kholik, A. A. 2018. Detection of cryptic taxa in the genus Leptophryne (Fitzinger,1843) (Ampibia; Bufonidae) and the description of a new species from Java, Indonesia. Zootaxa. 4450 (4): 42-44.

Harvey, M. B., O'Connell, K., Wostl, E., Riyanto, A., Kurniawan, N., Smith, E. N., Grismer, L. L. 2016. Redescription Cyrtodactylus lateralis (Werner) (Squamata: Gekkonidae) and phylogeny of the prehensile-tailed Cyrtodactylus. Zootaxa. 4107 (4): 517-540.

Harvey, M. B., Pemberton, A. J., Smith, E. N. 2002. New and poorly known parachuting frogs (Rhacophoridae: Rhacophorus) from Sumatra and Java. Herpetological Monographs. 16: 46-92.

Harvey, M. B., Shaney, K., Hamidy, A., Kurniawan, N., Smith, E. N. 2017a. A new species of Pseudocalotes (Squamata: Agamidae) from the Bukit Barisan range of Sumatra with an estimation of its phylogeny. Zootaxa. 4276 (2): 215-232.

Harvey, M. B., Shaney, K., Sidik, I., Kurniawan, N., Smith, E. N. 2017b. Endemic dragons of Sumatra's volcanoes: new species of Dendragama (Squamata: Agamidae) and status of Salea rosaceum Thominot. Herpetological Monographs. 31: 69-97.

Inger R. F \& Iskandar, D. T. 2005. A collection of amphibians from west Sumatra, with description of a new species of Megophrys (Amphibia: Anura). The Raffles Bulletin of Zoology. 53 (1): 133-142.
Inger, R. F \& Stuebing R. B. 2005. A field guide to the frogs of Borneo. Natural History Publication. Kinabalu.

Inger, R. F \& Voris, H. K. 2001. The biogeographical relations of the frogs and snakes of Sundaland. Journal of Biogeography. 28: 863-891.

Iskandar, D. T. 1998. The Amphibians of Java and Bali. LIPI. Bogor.

Kusrini, M. D. 2008. Pedoman penelitian dan survei amfibi di alam. Fakultas Kehutanan IPB. Bogor.

Munir, M., Hamidy, A., Farajallah, A., Smith, E. N. 2018. A new Megophrys Kuhl and Van Hasselt (Amphibia: Megophrydae) from southwestern Sumatra, Indonesia. Zootaxa. 4442 (3): 389-412.

Nugraha, F. A. D., Selaras, G. H., Satria, R. 2019. Preliminary checklist of herpetofauna of mount Sago along the hiking trail in the dry season in International conference on biology, sciences and education. Advances in Biological Sciences Research. 10: 51-55.

Putra, A. C., Amarasinghe, T. A. A., Hikmatullah, D., Scali, S., Brinkman, J., Manthey, U., Ineich, I. 2020. Rediscovery of Modigliani's nose-horned lizard, Harpesaurus modiglianii Vinciguerra, 1933 (Reptilia: Agamidae) after 129 years without any observation. TAPROBANICA. 9 (1): 3-11.

Smart, U., Sarker, G. C., Arifin, U., Harvey, M. B., Sidik, I., Hamidy, A., Kurniawan, N., Smith, E. N. 2017. A new genus and two new species of arboreal toads from the highlands of Sumatra with a phylogeny of Sundaland toad genera. Herpetologica. 73 (1): 63-75.

Teynie, A., David, P., Ohler, A. 2010. Note on a collection of amphibians and reptiles from Western Sumatra (Indonesia), with the description of a new species of the genus Bufo. Zootaxa. 2416: 1-43.

Wostl, E., Riyanto, A., Hamidy, A., Kurniawan, N., Smith, E. N., Harvey, M. B. 2017. A taxonomic revision of the Philautus (Anura: Rhacoporidae) of Sumatra with the description of four new species. Herpetological Monographs. 31 (1): 70113. 